\title{
Metabolic Studies of Human Bone In Vitro. I. Normal Bone *
}

\author{
Barry Flanagan $\dagger$ and George Nichols, Jr. $\ddagger$ \\ (From the Department of Medicine, Harvard Medical School and Peter Bent Brigham Hospital, \\ Boston, Mass.)
}

It has long been apparent that the key to understanding the pathophysiology of metabolic bone disease lies in understanding human skeletal physiology at the tissue level. Although some gross and microscopic structural disturbances (1, 2 ) and changes in total skeletal mineral content (3) have been correlated with certain types of metabolic bone disease, rates of accretion and resorption have been studied systematically only in terms of the turnover and retention of isotopes in the mineral phase of the skeleton (4-9). Similar studies with respect to the organic matrix have been severely limited by the lack of suitable methodology, although some useful information has been obtained by indirect means (10-16). The development of methods for studying the metabolic patterns of bone in vitro in this and other laboratories (17-20) has opened the way to direct exploration of the patterns and rates of cellular metabolism present in normal and abnormal human bone.

The patterns of metabolism found in vitro in bone samples from a group of normal human

\footnotetext{
* Submitted for publication November 10, 1964; accepted July 15, 1965.

Supported largely by the John H. Hartford Foundation of New York and in part by grant AM 00854-09 from the Institute of Arthritis and Metabolic Diseases of the National Institutes of Health and the general research support grant from the National Institutes of Health to the Peter Bent Brigham Hospital. Some of the patients were hospitalized in the Clinical Research Center of the Peter Bent Brigham Hospital, supported by grant 8M01FR-31-04 of the National Institutes of Health, U. S. Public Health Service.

Presented in part at the national meeting of the American Federation for Clinical Research, Atlantic City, N. J., May 3, 1964.

+ Postdoctoral fellow, Division of Arthritis and Metabolic Diseases, U. S. Public Health Service.

$\ddagger$ Address requests for reprints to Dr. George Nichols, Jr., Dept. of Medicine, Harvard Medical School, Boston, Mass. 02115.
}

subjects are described in this work and compared to those found in two species of animals. Alterations of these patterns found in skeletal disorders of various kinds will be the subjects of future works. The animal data have been included in order to indicate the degree to which patterns of bone metabolism are similar in man and lower mammalian forms-information of critical importance if the results of animal experiments are to be used to interpret the changes in bone metabolism observed in human bone disease.

\section{Methods}

Bone samples from eight adult human subjects ranging in age from 17 to 67 years who were undergoing surgery for a variety of orthopedic conditions but had no evidence of metabolic bone disease were used in the in vitro metabolic studies. In addition, four samples of bone from children obtained at autopsy and two samples from an elderly patient with avascular necrosis of the femoral head were analyzed to determine the relative cellularity of various types of human bone. The majority of samples comprised a mixture of cortical and trabecular bone derived from the iliac crest, but a few from other sites were included, as indicated in Table I. As no quantitative or qualitative metabolic differences were found between rib and iliac crest, the results from both types of samples were combined in analyzing the metabolic data.

Identical metabolic studies were carried out on bone from three groups of rats of the Sprague-Dawley strain of varying ages, one newly weaned domestic pig, and one Pitman-Moore miniature pig. ${ }^{1}$ Bone from the proximal tibial and distal femoral metaphyseal areas was pooled and mixed before samples were removed for study. In the case of the rats, bone from two to six animals of each age was pooled and duplicate samples were taken for each study.

All bone samples were collected directly into chilled ( 2 to $4^{\circ} \mathrm{C}$ ) isotonic saline or Krebs-Ringer medium buffered with bicarbonate and $5 \% \mathrm{CO}_{2}$ at $\mathrm{pH} 7.4$ and maintained at this temperature throughout the preparative handling procedures. Adherent soft tissue and periosteum

1 Originally developed by Vita-Vet Laboratories, Marvin, Ind., and kindly supplied by Dr. B. Trum, Animal Research Center, Harvard Medical School. 
were removed, and the samples were then chopped into fragments of approximately $2 \mathrm{~mm}^{3}$ and rinsed three times in Krebs-Ringer medium to free them of marrow cells as much as possible. Portions of washed bone fragments were weighed after blotting on a Roller-Smith balance before incubation. Autopsy samples were prepared similarly but were not incubated.

Oxygen utilization rates were measured in a Warburg respirometer. Human bone samples weighing between 300 and $500 \mathrm{mg}$ and animal samples weighing between 150 and $300 \mathrm{mg}$ were incubated in $2.0 \mathrm{ml}$ of KrebsRinger medium buffered with phosphate at $\mathrm{pH} 7.4$ with $11.1 \mathrm{mM}$ glucose added. Incubations were carried out at $37.5^{\circ} \mathrm{C}$ with continuous shaking under an atmosphere of $100 \%$ oxygen. Incubation times varied from 3 to 6 hours.

Samples of human and animal bone weighing 200 to 400 $\mathrm{mg}$ were used to study glucose and proline incorporation rates and lactate production. The weighed portions were placed in $25.0-\mathrm{ml}$ Erlenmeyer flasks with $2.0 \mathrm{ml}$ of KrebsRinger bicarbonate buffered medium, $\mathrm{pH} \mathrm{7.4,} \mathrm{containing}$ $11.1 \mathrm{mM}$ glucose. Incubations were carried out in a Dubnoff metabolic incubator at $37.5^{\circ} \mathrm{C}$, with continuous shaking (100 cycles per minute), under an atmosphere of $95 \% \mathrm{O}_{2}$ and $5 \% \mathrm{CO}_{2}$ for 2 to 4 hours. In studies of glucose incorporation, glucose- $\mathrm{U}_{-14}{ }^{14} \mathrm{C}$ was added to the medium to give an initial specific activity of approximately $0.23 \mathrm{mc}$ per mmole. In studies of proline incorporation, carrier proline at a $0.5 \mathrm{mM}$ concentration was added with enough proline-U- ${ }^{14} \mathrm{C}$ to provide an initial specific activity of about $0.46 \mathrm{mc}$ per mmole. The exact initial specific activity of the medium was measured in each experiment.

After incubation the entire contents of the Warburg flasks were decanted and the flasks rinsed twice with two $1.0-\mathrm{ml}$ washes of distilled water. The rinses were added to the decanted materials, and $4.0 \mathrm{ml}$ of $0.2 \mathrm{~N}$ $\mathrm{NaOH}$ was added to give a final alkali concentration of $0.1 \mathrm{~N}$. Autopsy samples were extracted directly with measured portions of $0.1 \mathrm{~N} \mathrm{NaOH}$.

The vials were shaken overnight at room temperature to extract the noncollagenous nitrogen. This alkali extract contained, in addition to the bone cell proteins, all of the tissue DNA and some extracellular nitrogen including any alkali soluble collagen and mucopolysaccharide (20). It is referred to in the Tables as the "cell" fraction.

The media of the Dubnoff flasks were chilled, decanted, and centrifuged after incubation, and samples of the supernate were taken for the determination of lactate. The bone fragments were washed three times in chilled nonradioactive medium and extracted with $2.0 \mathrm{ml}$ of $0.1 \mathrm{~N}$ $\mathrm{NaOH}$ as noted.

After alkali extraction, the alkali soluble material was decanted and stored. The extracted bone fragments were decalcified by shaking at $2^{\circ} \mathrm{C}$ in three successive washes of $10 \%$ EDTA, $\mathrm{pH} 7.5$, for 48 hours. The fragments were then successively washed with water and acetone, and finally re-extracted for 24 hours with a 1:1 mixture of ethanol: ether. In some samples with obviously high
TABLE I

Relative cellularity of normal human bone*

\begin{tabular}{|c|c|c|c|}
\hline \multicolumn{2}{|c|}{ Cortical } & \multicolumn{2}{|c|}{ Mixed } \\
\hline Age & $\begin{array}{c}\text { DNA } \\
\text { content }\end{array}$ & Age & $\begin{array}{c}\text { DNA } \\
\text { content }\end{array}$ \\
\hline years & $\underset{\text { wet wt }}{m g / 100 ~ m g}$ & years & $\underset{\text { wet wt }}{m g / 100 ~ m g}$ \\
\hline $\begin{array}{l}16 \\
17 \\
38 \\
62 \dagger\end{array}$ & $\begin{array}{l}0.146 \\
0.120 \\
0.051 \\
0.034\end{array}$ & $\begin{array}{c}\text { Newborn } \\
7 \\
8 \\
12 \\
17 \\
28 \\
35 \ddagger \\
42 \\
67 \ddagger\end{array}$ & $\begin{array}{l}0.520 \\
0.495 \\
0.595 \\
0.409 \\
0.176 \\
0.282 \\
0.101 \\
0.216 \\
0.119\end{array}$ \\
\hline
\end{tabular}

* Unless otherwise noted, samples were derived from the iliac crest.

$\dagger$ Derived from rib.

$\ddagger$ Derived from the greater trochanter.

fat contents lipid extraction with petroleum ether (bp $40^{\circ}$ to $60^{\circ} \mathrm{C}$ ) was carried out before alkali extraction. The remaining material, relatively pure collagen (20), was dissolved in a small volume of either concentrated formic acid or constant boiling hydrochloric acid before counting of radioactivity. ${ }^{2}$

The glucose content of incubation media was determined by the method of Nelson (22), as modified by Somogyi (23), and the proline content by the method of Chinard (24). Lactate was measured by the method of Barker and Summerson (25). The DNA content of the alkali extracts of the Warburg and autopsy samples was measured by the hot trichloroacetic acid extraction method of Schneider (26). The DNA content of the Dubnoff flasks was calculated from the initial wet weight of the bone samples and the measured DNA wet weight ratio of samples from the Warburg flasks. This method was preferred to the direct determination of DNA on the Dubnoff alkali extracts because of the possibility of significant and variable DNA losses to the medium during incubation.

Radioactivity of samples was measured in a Packard Tri-Carb liquid scintillation counter, with toluene as a solvent and 2,5-diphenyloxazole (4 g per $\mathrm{L}$ ) and 1,4-bis2-(5-phenyloxazolyl)benzene ( $50 \mathrm{mg}$ per $\mathrm{L}$ ) as primary and secondary fluors. Small volumes $(10$ to $100 \mu 1)$ of initial medium, sodium hydroxide extracts, and solutions of the collagen fractions were dispersed in the scintillation mixture by the addition of $1.5 \mathrm{ml}$ of $1.0 \mathrm{M}$ hyamine hydroxide in methanol. All samples were internally standardized using ${ }^{14} \mathrm{C}$ toluene. Recoveries varied from 75 to $95 \%$, with a machine efficiency between 70 and $75 \%$.

The incorporation of glucose and proline into cell and collagen fractions was calculated using the total counts recovered in each fraction and the specific activities of glu-

${ }^{214} \mathrm{C}$-label derived from the medium proline has been found in the proline and hydroxyproline of this fraction only (20), whereas label from medium glucose has been found in all the nonessential amino acids (21). 


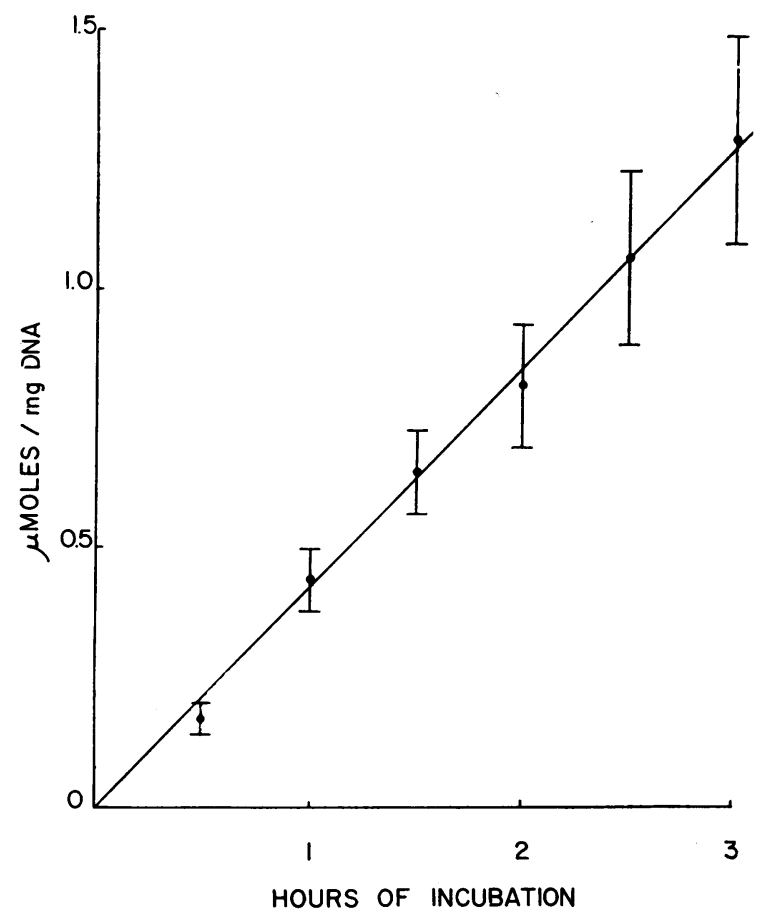

Fig. 1. The cumulative oxygen Utilization of HUMAN BONE WITH TIME. Each point represents the mean value found in bone from seven individuals. One standard error above and below the mean is indicated for each mean by the vertical bar.

cose and proline in the initial media. All results were finally expressed per milligram tissue DNA per hour.

\section{Results}

The cellularity of the various human bone samples as estimated by DNA content varied considerably, as can be seen from Table I. Whereas the two rib samples appeared to contain less cells per unit of weight than the iliac crest, the major causes of variability appeared to be the age of the subject and the type of bone. Thus, cortical bone samples contained approximately

TABLE II

The comparative $\mathrm{O}_{2}$ utilization rates of human and animal bone

\begin{tabular}{|c|c|c|c|c|}
\hline & Age & Mean & SEM* & $\begin{array}{c}\text { No. of } \\
\text { samples }\end{array}$ \\
\hline & \multicolumn{4}{|c|}{ umoles $\mathrm{O}_{2} / \mathrm{mg} D N A /$ hour } \\
\hline Human & Adult & 0.47 & 0.09 & 8 \\
\hline Domestic pig & 35 days & 1.24 & 0.09 & 5 \\
\hline Rat & 55 days & 1.98 & 0.07 & 10 \\
\hline
\end{tabular}

* SEM $=$ standard error of the meall. one-quarter as many cells as did mixed bone (cortical and trabecular) and showed a clear reduction with advancing age. Similarly mixed bone from children was more cellular than that of adults. However, the disparity between the cellular contents of cortical and trabecular bone was apparently large enough to suggest that the relative amounts of these two types of bone that are included in any sample (at least in adults) rather than the site of biopsy will determine its cellularity.

The cumulative oxygen utilization of a group of normal human bone samples is shown in Figure 1 to illustrate that during a 3-hour incubation the $\mathrm{O}_{2}$ utilization rate remained quite constant. Indeed, longer incubations of similar samples have shown that this rate continues to be linear

TABLE III

Aerobic lactate production of human and animal bone

\begin{tabular}{|c|c|c|c|c|}
\hline & Age & Mean & SEM & $\begin{array}{l}\text { No. of } \\
\text { samples }\end{array}$ \\
\hline \multicolumn{5}{|c|}{ mmoles/mg DNA/hour } \\
\hline Human & Adult & 0.79 & 0.12 & 6 \\
\hline Domestic pig & 35 days & 1.09 & 0.06 & 6 \\
\hline \multirow[t]{3}{*}{ Rat } & 40 days & 2.94 & 0.17 & 4 \\
\hline & 65 days & 1.93 & 0.12 & 5 \\
\hline & 85 days & 1.15 & 0.11 & 4 \\
\hline
\end{tabular}

for at least 6 hours, a degree of stability seen also in animal bone under similar in vitro conditions $(17,19-21)$.

In view of this steady state of metabolism, the rates of other metabolic processes were measured over time periods of 3 or 4 hours and expressed per milligram DNA per hour.

The $\mathrm{O}_{2}$ utilization rates of adult human bone and bone from young growing rat and pig are compared in Table II. The relatively narrow range of variation found in normal adult human bone when expressed in terms of DNA content was of interest, especially in view of the wide range of ages of the subjects and the different skeletal areas represented by the samples. As might be expected $\mathrm{O}_{2}$ consumption was greater in the bone of the two animal species studied. These were young and actively growing, a situation in which metabolic rates higher than those seen in adult animals have been observed (27). Moreover, the greater $\mathrm{O}_{2}$ utilization seen in rat 
TABLE IV

Proline incorporation in human and animal bone

\begin{tabular}{|c|c|c|c|c|}
\hline Cell fraction & Age & Mean & SEM & $\begin{array}{c}\text { No. of } \\
\text { samples }\end{array}$ \\
\hline $\begin{array}{l}\text { Human } \\
\text { Miniature pig } \\
\text { Rat }\end{array}$ & $\begin{array}{l}\text { Adult } \\
60 \text { days } \\
40 \text { days } \\
65 \text { days } \\
85 \text { days }\end{array}$ & $\begin{array}{ll}\text { mumoles/mg } D N A / \text { hour } \\
23.4 \\
98.8 \\
113.0 \\
60.2 & \\
& \text { a) } 52.4^{*} \\
& \text { b) } 28.5\end{array}$ & $\begin{array}{l}3.5 \\
98.6 \text { to } 99.0 \dagger \\
4.8 \\
5.4\end{array}$ & $\begin{array}{l}6 \\
3 \\
4 \\
5 \\
2\end{array}$ \\
\hline $\begin{array}{l}\text { Collagen } \\
\text { Human } \\
\text { Domestic pig } \\
\text { Miniature pig } \\
\text { Rat }\end{array}$ & $\begin{array}{l}\text { Adult } \\
35 \text { days } \\
60 \text { days } \\
40 \text { days } \\
65 \text { days } \\
85 \text { days }\end{array}$ & 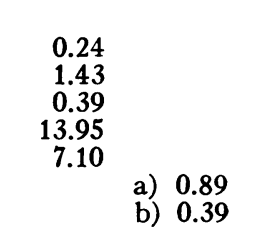 & $\begin{array}{c}0.04 \\
0.75 \text { to } 2.16 \dagger \\
0.33 \text { to } 0.53 \dagger \\
1.95 \\
0.49\end{array}$ & $\begin{array}{l}6 \\
3 \\
3 \\
4 \\
5 \\
2\end{array}$ \\
\hline
\end{tabular}

* Where there are two samples, the number is given for each sample.

$\dagger$ Range.

in comparison with pig bone suggested that the relatively higher basal metabolic rate seen in small compared to large animals might be reflected in the behavior of bone as well as other tissues.

Rates of bone aerobic lactate production [a striking feature of bone cell metabolism (17)] from the three species are compared in Table III. A tendency for lactate production to fall with increasing age is evident in the rat. As in the case of $\mathrm{O}_{2}$ consumption the absolute rates arrange themselves in the same descending order, rat $>$ pig $>$ human. Again, the relatively narrow range of lactate production exhibited by the samples of human bone should be noted.

Rates of incorporation of proline into the cell fraction and collagen of human bone samples are shown in Table IV with comparable data from rats of different ages and growing and mature pigs. The far larger incorporation of proline label into the cell fraction compared to collagen, which occurred in all species, presumably reflected labeling of cell amino acid pools and constituent proteins as well as accumulations of nascent collagen of high specific activity (28). The decreasing rate of both cell uptake and col-

TABLE $V$

Glucose incorporation in human and animal bone

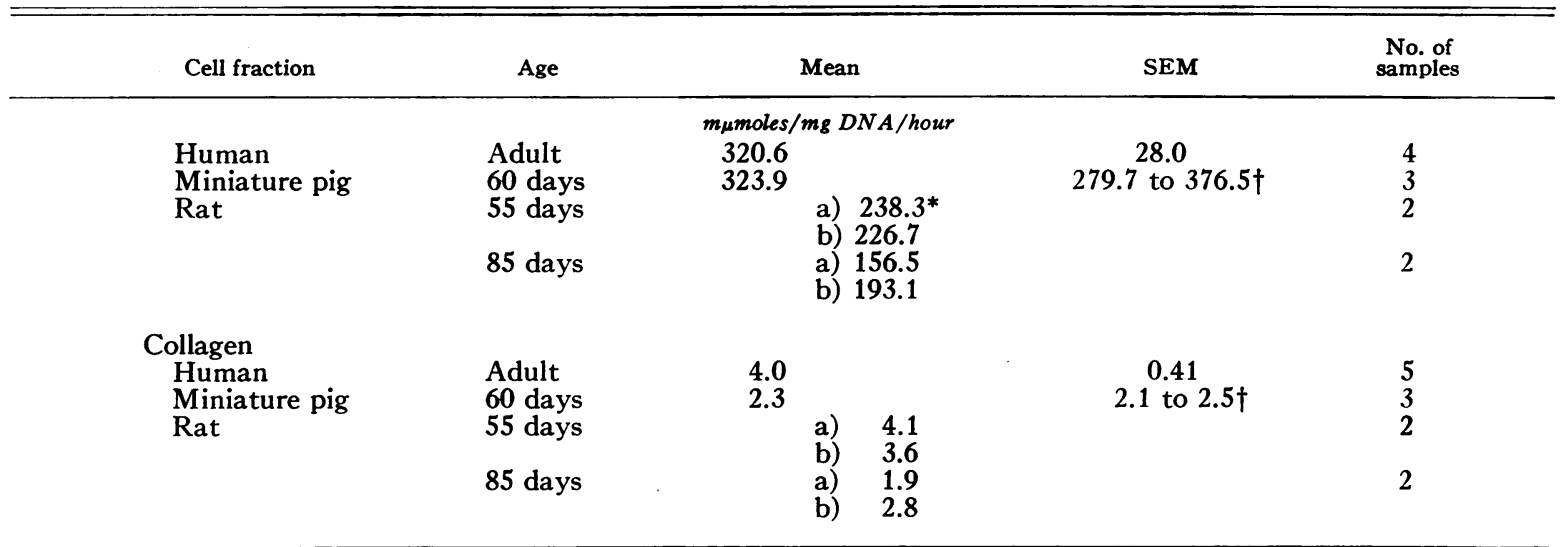

* Where there are two samples, the number is given for each sample.

$\dagger$ Range. 
lagen synthesis with age is clearly seen in the rat data (27). The rate of collagen synthesis in the growing pig exceeded that in the oldest rats, whereas the rate in the miniature pig was less than in the oldest rat group, and approached the value found in the adult human-observations compatible with the adult skeletal size present in both the miniature pig and the human subjects.

The relative rates of glucose uptake by the cell fraction and the utilization of glucose carbon for collagen synthesis (21) are presented in Table V. Again the incorporation of glucose label into the cell fraction was much larger than that into collagen in all cases. It should be noted that the much greater incorporation of glucose, compared to proline, into the cells probably resulted from the far greater concentration of this substrate in the incubation medium.

The clear-cut differences between man and animals were not observed in these experiments. Human and miniature pig bone both appeared to incorporate similar amounts of exogenous glucose, which exceeded those of both age groups of rats studied. The amount of incorporation of glucose into collagen was highest in the human group and was approached only by bone from the younger group of rats. The reasons for these differences in glucose compared to proline metabolism are unknown.

\section{Discussion}

The relative insensitivity of the methods used in these experiments imposed a number of limitations upon them. The large amount of bone needed $(1.2$ to $5 \mathrm{~g})$ required that the samples, which must be fresh, be obtained either incidental to major surgical procedures involving bone or by means of open biopsy, a procedure with too high a potential morbidity and disability for routine use. Moreover, the isolation of the cell fraction of the samples by alkali extraction imposed two further limitations. First, extracellular mucopolysaccharide is extracted with the cellular material, a "contaminant," which in relatively acellular samples such as human bone may well account for significant and variable proportions of the total $\mathrm{N}$ in such extracts $(20,29)$. In view of this total sample DNA has been used as a reference base in these experiments rather than the total cell fraction $\mathrm{N}$ used previ- ously $(17,20,21)$. More important, the alkali destroys the cell structure, RNA, and many enzymes, thus rendering detailed studies of cellular mechanisms impossible. Although newer methods (28) promise to solve some of these problems, their application to human material remains to be worked out. Thus it seemed preferable to use simpler methods whose limitations were well known $(17,20,21,27)$. Once the basic patterns of metabolism in normal and abnormal human bone were known it was felt that a more detailed examination of pertinent points could be undertaken.

Despite these limitations a number of significant points have emerged from these experiments. First, and most important, it is now clear that normal adult human bone in vitro, in common with bone from lower mammals, used $\mathrm{O}_{2}$ rather slowly but consumed glucose rapidly, converting the major portion of this substrate to lactate even under aerobic conditions. Moreover, exogenous proline as well as glucose was rapidly taken up into the bone cells where significant amounts of both substrates or their derivatives were incorporated into newly synthesized extracellular collagen.

Although the relation of the absolute rates of these processes measured in vitro to those occurring in vivo is not yet precisely known, the constancy of metabolic rate observed suggested that the phenomena observed were not just reflections of impending cell death.

The observation that metabolic rates in adult human bone calculated on the basis of DNA seem to be highly reproducible despite wide variations in the site of biopsy and varying proportions of cortical and trabecular bone has several implications of importance for future work. It indicates that as long as the DNA content of bone samples is used as the reference base, samples from a wide variety of skeletal sites may be used and compared. Moreover, it would appear that the most important factor controlling the over-all metabolic rate of bone in any given skeletal area in normal subjects is the number, rather than the relative metabolic activity, of the cells that it contains, a concept in keeping with previous observations in animals (27). Finally, it suggests that these rates are reasonable first approximations of the ranges of activity that are to be 
expected in bone from normal adults. These, in turn, may be used as standards with which bone metabolic data from patients suffering from metabolic bone disease can be compared.

Although some similarity in general metabolic pattern between human and animal bone was predictable, the agreement between the patterns in the three species proved much closer than had been anticipated. Indeed, the only differences observed were in absolute rate, which seemed attributable to differences in rates of bone growth and over-all body size rather than to differences in cellular metabolic pathways. The only possible exception was the disproportionately large uptake and utilization of glucose by human bone cells. Although the reasons for this difference cannot be determined from these experiments, it is possible that it is related to the greater relative age of the human subjects than of the animals studied (27).

As interesting as these similarities are from the general biological point of view, they have equal if not greater importance as a basis on which to build and test new hypotheses with respect to metabolic bone disease. It would seem reasonable to expect that animal systems with such similar metabolic patterns would respond in similar ways to a variety of influences such as age, sex, hormones, drugs. Thus, the use of the results of animal experiments in the interpretation of changes in bone metabolism in disease states would appear far more justifiable than previously seemed possible.

The metabolic rates measured in these studies pertain almost entirely to the biosynthesis of extracellular bone matrix and specifically its collagen component, whereas the biosynthesis of the mucopolysaccharide component of bone matrix has yet to be examined. Nevertheless, they provide information pertinent to establishing normal rates of new bone accretion and supplying a basis for examining disturbances of this aspect of skeletal physiology in disease $(30,31)$. They do not, however, provide any direct information regarding rates of bone resorption; only the rate of lactate production has any apparent relation to this invariable partner of accretion in the bone turnover process. Although in the normal adult bone resorption can be presumed to equal accretion, such an assumption is untenable in states of metabolic bone disease. Therefore, a complete description of the physiological disturbances at the cellular level occurring in metabolic bone diseases will have to wait until methods to estimate bone matrix resorption in vitro, now being developed, have been adapted to human material $(32,33)$.

\section{Summary}

1) The feasibility of studying the cellular metabolic patterns of samples of fresh human bone obtained at biopsy by incubation in vitro has been demonstrated.

2) The metabolism in vitro of bone from normal adults remains constant for sufficient time to allow quantitative estimates of the rates of certain metabolic processes including the biosynthesis of collagen.

3) Metabolic rates in adult human bone samples obtained from a variety of ages and skeletal sites proved to be closely similar when calculated on the basis of sample DNA, despite considerable variation in cell content.

4) The following rates of metabolism in the bone of normal adults, expressed per milligram of sample DNA per hour, were observed: oxygen consumption, $0.47 \pm 0.09 \mu$ mole; lactate production, $0.79 \pm 0.12 \mu$ mole; incorporation of labeled proline into cells, $23.4 \pm 3.5 \mathrm{~m} \mu$ moles, into collagen, $0.24 \pm 0.04 \mathrm{~m} \mu$ mole; incorporation of labeled glucose into cells, $320.6 \pm 28.0 \mathrm{~m} \mu$ moles, into collagen, $4.0 \pm 0.41 \mathrm{~m} \mu$ moles.

5) Metabolic patterns in human bone and those of two lower mammals (pigs and rats) have been compared and their qualitative similarities noted. These similarities appear to justify the use of information derived from animal experiments in the interpretation of phenomena observed in human samples.

6) The implications of these observations with respect to investigating the origins of human metabolic bone disease have been discussed.

\section{Acknowledgments}

We are greatly indebted to Drs. H. Banks, W. Green, and $T$. Quigley for supplying the human bone samples. The skilled technical assistance of Mrs. Norma Steiriberg, Mrs. Susan Ault, and Miss Hanne Alstrup is gratefully acknowledged. 


\section{References}

1. Urist, M. Observations bearing on the problem of osteoporosis in Bone as a Tissue, K. Rodahl, J. T. Nicholson, and E. M. Brown, Eds. New York, McGraw-Hill, 1960, p. 18.

2. Robinson, R. Chemical analysis and electron microscopy of bone in Bone as a Tissue, K. Rodahl, J. T. Nicholson, and E. M. Brown, Eds. New York, McGraw-Hill, 1960, p. 186.

3. Albright, F., and E. Reifenstein. The Parathyroid Glands and Metabolic Bone Disease. Baltimore, Williams \& Wilkins, 1948, p. 303.

4. Heaney, R. P. Radiocalcium metabolism in disuse osteoporosis in man. Amer. J. Med. 1962, 33, 188.

5. Rich, C., J. Ensinck, and H. Fellows. The use of continuous infusions of calcium ${ }^{45}$ and strontium ${ }^{85}$ to study skeletal function. J. clin. Endocr. 1961, 21, 611.

6. Corey, K. R., P. Kenney, E. Greenberg, A. Pazianos, O. H. Pearson, and J. S. Laughlin. The use of calcium 47 in diagnostic studies of patients with bone lesions. Amer. J. Roentgenol. 1961, 85, 955.

7. Lafferty, F. W., and O. H. Pearson. Skeletal, intestinal and renal calcium dynamics in hyperparathyroidism. J. clin. Endocr. 1963, 23, 891.

8. Smeenk, D. Studies of bone of patients with hyperparathyroidism by means of phosphate exchange experiments in vitro and quantitative microradiography. J. clin. Invest. 1961, 40, 433.

9. Neuman, W., and M. Neuman. The Chemical Dynamics of Bone Mineral. Chicago, University of Chicago Press, 1958, p. 64.

10. Gutman, A. B., T. L. Tyson, and E. B. Gutman. Serum calcium, inorganic phosphorus and phosphatase activity in hyperparathyroidism, Paget's disease, multiple myeloma and neoplastic disease of the bones. Arch. intern. Med. 1936, 57, 379.

11. Kay, H. D. Phosphatase in growth and disease of bone. Physiol. Rev. 1932, 12, 384.

12. Klein, L., K. Albertsen, and P. H. Curtiss, Jr. Urinary hydroxyproline in hyperparathyroidism: a study of three cases with and without bone lesions. Metabolism 1962, 11, 1023.

13. Jasin, H. E., C. W. Fink, W. Wise, and M. Ziff. Relationship between urinary hydroxyproline and growth. J. clin. Invest. 1962, 41, 1928.

14. Bronner, F. Parathyroid effects on sulphate metabolism: interrelationships with calcium in The Parathyroids, R. O. Greep and R. V. Talmage, Eds. Springfield, I11., Charles C Thomas, 1961, p. 123.

15. Milch, R. A., D. P. Rall, and J. E. Tobie. Fluorescence of tetracycline antibiotics in bone. J. Bone Jt Surg. 1958, 40-A, 897.

16. Sissons, H. A. Osteoporosis of Cushings syndrome in Bone as a Tissue, K. Rodahl, J. T. Nicholson, and
E. M. Brown, Eds. New York, McGraw-Hill, 1960, p. 3.

17. Borle, A., N. Nichols, and G. Nichols, Jr. Metabolic studies of bone in vitro. I. Normal bone. J. biol. Chem. 1960, 235, 1206.

18. Kenny, A. D. Citric acid production by bone in The Parathyroids, R. O. Greep and R. V. Talmage, Eds. Springfield, I11., Charles C Thomas, 1961, p. 275.

19. Deiss, W. P., Jr., L. B. Holmes, and C. C. Johnston, $\mathrm{Jr}$. Bone matrix biosynthesis in vitro. I. Labeling of hexosamine and collagen of normal bone. J. biol. Chem. 1962, 237, 3555.

20. Flanagan, B., and G. Nichols, Jr. Metabolic studies of bone in vitro. IV. Collagen synthesis by surviving bone fragments in vitro. J. biol. Chem. 1962, 237, 3686.

21. Flanagan, B., and G. Nichols, Jr. Metabolic studies of bone in vitro. V. Glucose metabolism and collagen biosynthesis. J. biol. Chem. 1964, 239, 1261.

22. Nelson, N. A photometric adaptation of the Somogyi method for the determination of glucose. J. biol. Chem. 1944, 153, 375.

23. Somogyi, M. Notes on sugar determination. J. biol. Chem. 1952, 195, 19.

24. Chinard, F. P. Photometric estimation of proline and ornithine. J. biol. Chem. 1952, 199, 91.

25. Barker, S. B., and W. H. Summerson. The colorimetric determination of lactic acid in biological material. J. biol. Chem. 1941, 138, 535.

26. Schneider, W. C. Methods in Enzymology. New York, Academic Press, 1957, vol. 3, p. 680.

27. Nichols, G., Jr. Age induced changes in composition and metabolism of two types of rat bone. In press.

28. Nichols, G., Jr. Collagen biosynthesis in bone. Presented at the NATO Advanced Study Institute on The Structure and Function of Connective and Skeletal Tissues, June 1964. In press.

29. Simmons, D. J., and G. Nichols, Jr. Diurnal variations in bone and cartilage tissue. In press.

30. Flanagan, B., and G. Nichols, Jr. Direct measurements of human bone metabolism in normal and hyperparathyroid subjects (abstract). Clin. Res. 1964, 12, 266.

31. Nichols, G., Jr., B. Flanagan, and J. F. Woods. Parathyroid influences on bone biosynthetic mechanisms in The Parathyroid Glands, P. J. Gaillard, R. V. Talmage, and A. M. Budy, Eds. Chicago, University of Chicago Press, 1965, p. 243.

32. Woods, J. F., and G. Nichols, Jr. Collagenolytic activity in mammalian bone. Science 1963, 142, 386.

33. Woods, J. F., and G. Nichols, Jr. The intracellular location of bone "collagenase." Fed. Proc. 1964, 23, 550. 